\title{
Rousseau y Kant frente al problema del carácter vinculante de las normas Derecho de gentes
}

\author{
Rousseau and Kant on the Problem \\ Regarding the Binding Character of the \\ Norms of International Right
}

\author{
Ileana Beade ${ }^{1}$ \\ CONICET (Argentina)
}

ORCID: https://orcid.org/0000-0002-1944-9516

Recibido: 15-05-2020

Aceptado: 14-07-2020

\section{Resumen}

En sus respectivos proyectos para la consolidación del Derecho de gentes, Rousseau y Kant abordan la cuestión referida al carácter vinculante de las normas jurídicas internacionales. Mientras Rousseau sostiene que, a fin garantizar la eficacia de tales normas, sería necesario constituir un poder coactivo supranacional autorizado para obligar a los Estados europeos a integrar la confederación, a permanecer en ella y a imponer sanciones coercitivas a aquellos que incumplan las normas establecidas, Kant considera que semejante poder amenazaría la soberanía de los Estados, y se inclina por una confederación de Estados libres, no sujetos a un poder coactivo común. En este trabajo se examinarán las premisas bajo las cuales los autores abordan este importante problema, premisas a partir de las cuales cabe explicar la posición que cada uno de ellos asume ante el problema de la regulación jurídica de las relaciones internacionales.

\footnotetext{
${ }^{1}$ (ileanabeade@yahoo.com.ar). Doctora en Filosofía por la Universidad Nacional de Rosario (UNR, Argentina), Doctora en Ciencia Política (UNR), Magíster en Ciencias Sociales por la FLACSO (Facultad latinoamericana de Ciencias Sociales), e Investigadora del Consejo Nacional de Investigaciones Científicas y Técnicas (CONICET). Se desempeña como Profesora de las Cátedras de Historia de la Filosofía Moderna y de Problemática Política en la UNR. Es miembro fundador de la Sociedad de Estudios Kantianos en Lengua Española (SEKLE) y miembro del Grupo de Estudios Kantianos (GEK, Universidad de Buenos Aires).
} 
Palabras-clave: Paz, Derecho internacional, Coerción, Confederación.

\begin{abstract}
In their respective projects to consolidate the institutions of International Right, Rousseau and Kant address the issue concerning the binding character of international juridical norms. While Rousseau states that it is necessary to constitute a coercive supranational power, authorized to force the European States to enter the International confederation, to compel them to remain in it and to enforce international laws, Kant considers that such a power would threaten the sovereignty of the States, and leans towards a confederation of free States, not subordinated to a common coercive power. In this paper I analyze the premises which underlie each of these approaches and that might help to understand the different positions assumed by Rousseau and Kant regarding the problem of the juridical regulation of international relations.
\end{abstract}

Keywords: Peace, International Right, Coercion, Confederation.

Covenants, without the sword, are but words and of

no strength to secure a man at all (Hobbes 1996: 137).

\title{
Introducción
}

En su Resumen del proyecto de paz perpetua del Abate de Saint-Pierre [Extrait du Projet de Paix Perpétuelle] ${ }^{2}$, Rousseau aborda uno de los problemas fundamentales que se plantean en torno a la consolidación de las normas del Derecho de gentes (o, en términos contemporáneos, del Derecho Internacional

\footnotetext{
${ }^{2}$ En 1754 dos amigos del Abate encomiendan a Rousseau la elaboración de un resumen de las ideas más importantes de aquél, y así surge el Extrait du Projet de Paix Perpétuelle, que en los años sucesivos será traducido al francés, al inglés y al alemán; es así "como Rousseau se convirtió en pieza clave en la difusión del cosmopolitismo y del plan de Saint-Pierre en la segunda mitad del siglo" (Espinosa Antón 2014: 14). El resumen de Rousseau no es una mera presentación sintética del proyecto del Abate: el propio editor del escrito de Rousseau observa que aparecen expresadas, en el resumen, posiciones e ideas propias del pensador ginebrino (Granja Castro, D. M. \& Charpenel Elorduy, E., Op. cit., pp. 40-41; Rubio Carracedo, pp. 155-157). El Extrait es un escrito clave para el análisis de la posición asumida por Rousseau respecto del Derecho de gentes. Como sabemos, El contrato social constituía, según el plan inicial de su autor, la primera parte de una obra titulada Instituciones políticas, cuya segunda parte estaría dedicada al problema de la regulación jurídica de los conflictos entre las naciones. La obra completa no llegó a escribirse, con lo cual, la reconstrucción de las ideas de Rousseau acerca de dicho problema exige examinar escritos diversos, entre los cuales se destacan el Discurso sobre la desigualdad, el Resumen sobre el tratado del Abate de Saint Pierre y el Juicio sobre el mismo tratado (Truyol y Serra 1979: 49s.)
} 
Público), a saber: cómo garantizar la eficacia de tales normas, dadas las dificultades y desventajas que supone la institución de un poder coactivo supranacional. Luego de referirse a los indudables beneficios de un "gobierno de forma confederativa, el cual, al unir los pueblos por lazos semejantes a los que unen a los individuos, somete igualmente a unos y a otros a la autoridad de las leyes" (Rousseau 2006, RPP: 20) ${ }^{3}$, observa que, si bien las naciones europeas se hallan estrechamente vinculadas, Europa está amenazada por un constante antagonismo: "la antigua unión de los pueblos de Europa ha complicado sus intereses y sus derechos de mil maneras: se tocan por tantos puntos que el menor movimiento en unos provoca el choque de los otros; sus divisiones son tanto más funestas cuanto que sus lazos son más íntimos; y sus frecuentes querellas tienen casi la crueldad de las guerras civiles" (Rousseau 2006, RPP: 23). El autor propone, como solución a esta situación de conflicto, la creación de una confederación de Estados europeos dotada de un poder centralizado, "un poder efectivo, capaz de forzar a los ambiciosos a mantenerse dentro de los límites del tratado general" (Rousseau 2006, RPP: 28). Sin la institución de un poder tal, la confederación quedaría reducida a un mero conjunto de compromisos vanos, que cualquier Estado podría cancelar de manera impune.

Por su parte, Kant aborda la cuestión referida a una regulación jurídica de las relaciones interestatales en escritos pertenecientes a diversos períodos, entre los que cabría destacar: Idea para una historia universal en clave cosmopolita [Idee zu einer allgemeinen Geschichte in weltbürgerlicher Absicht, 1784], En torno al tópico: "Tal vez eso sea correcto en teoría, pero no sirve para la práctica» [Über den Gemeinspruch: Das mag in der Theorie richtig sein, taugt aber nicht für die Praxis, 1793], Hacia la paz perpetua [Zum ewigen Frieden, 1795] y, finalmente, La metafísica de las costumbres [Die Metaphysik der Sitten, 1797] $]^{4}$. Si bien su propuesta para la institución de una confederación internacional orientada a la resolución pacífica de los conflictos interestatales se irá modificando a lo largo del tiempo ${ }^{5}$, en Hacia la paz perpetua propone la creación de una confederación de Estados libres, no sujeta a un poder coactivo supranacional.

En este trabajo se analizarán las premisas que subyacen a las propuestas de ambos pensadores, a partir de las cuales es posible explicar sus divergencias

\footnotetext{
${ }^{3}$ De aquí en adelante se hará referencia al Resumen bajo la abreviatura: RPP.

${ }^{4}$ De aquí en adelante, siguiendo el uso convencional en el ámbito de los estudios kantianos, se citará la paginación correspondiente a la edición académica de las obras kantianas: Kants gesammelte Schriften (vol. I-IX), Berlin, Herasugegeben von der Königlich Preussischen Akademie der Wissenschaften, 1902ss. A esta edición aludimos bajo la abreviatura Ak., seguida del número de tomo, indicado en números romanos. Se hará referencia a los escritos mencionados bajo las siguientes abreviaturas: IaG (Idea para una historia universal en clave cosmopolita), TP (En torno al tópico: «Tal vez eso sea correcto en teoría, pero no sirve para la práctica»), ZeF (Hacia la paz perpetua) y MS (La metafisica de las costumbres).

${ }^{5}$ Para un estudio de las modificaciones en la posición asumida por Kant respecto del problema de los conflictos internacionales, vid. Kleingeld 2009: 171ss.; Byrd \& Hruschka 2010: 196-204.
} 
respecto de la conveniencia (o inconveniencia) de erigir un poder supranacional autorizado para el ejercicio legítimo de la coacción, cuestión que no ha perdido relevancia en la actualidad, en vistas de los problemas y obstáculos que enfrentan, en el presente, las instituciones del Derecho internacional público.

\section{Rousseau y el proyecto de una confederación internacional europea}

En su Resumen del proyecto del Abate de Saint-Pierre, Rousseau comienza por señalar que las asociaciones federativas existían ya desde la antigüedad: los griegos, etruscos, latinos y galos ensayaron diversas asociaciones de ese tipo, además de aquellas que surgieron, no a través de normas expresamente consensuadas, sino mediante la unión espontánea entre los pueblos, a partir de la existencia de intereses comunes, la uniformidad de las costumbres, las creencias religiosas o los vínculos comerciales. A través de estos mecanismos informales de asociación, se fue consolidando, desde antaño, la idea de un derecho de gentes ${ }^{6}$. Sin embargo, pese a esas tentativas, y a la existencia de proyectos más recientes orientados a promover la paz, hasta el momento los tratados internacionales no permiten sino treguas momentáneas, insuficientes para asegurar una paz duradera y estable. Ello se debe al hecho de que tales tratados no suelen tener más garantía que la mera voluntad de las partes contratantes. El autor se pregunta, entonces, bajo qué condiciones la asociación libre y espontánea que vincula a los Estados europeos podría dar lugar al establecimiento de una confederación verdaderamente eficaz. Si bien confía en que una federación europea "al dar a esta asociación la perfección que le falta, destruirá los abusos, extenderá las ventajas y forzará a todas las partes a concurrir al bien común", advierte sin embargo que

es preciso para ello que esta confederación sea efectivamente general, de modo que ninguna potencia considerable la rehúse; que exista un tribunal judicial que pueda establecer leyes y reglamentos que han de obligar a todos los miembros; que exista una fuerza coactiva para imponer a cada Estado el que se someta a las deliberaciones comunes, sea para actuar, sea para abstenerse de hacerlo; en

\footnotetext{
${ }^{6}$ Respecto del diagnóstico rousseauniano acerca de la situación europea, señala Truyol: "Reconoce Rousseau [...] que las relaciones internacionales no carecen de toda norma jurídica, puesto que se ha ido desarrollando una rama del derecho que tiene precisamente por objeto su regulación: se refiere al derecho de gentes (hoy más comúnmente conocido como derecho internacional), que en su siglo alcanzó un notorio desarrollo tanto institucional como doctrinal. Pero acto seguido afirma su debilidad e inoperancia. [...] En realidad, Rousseau podría haber alegado además que el propio derecho de gentes de la época admitía la guerra como institución. Se concebía, en efecto, como una institución necesaria, por la ausencia de un superior que pudiese resolver los conflictos entre Estados soberanos, y el derecho de gentes se conformaba con regularla para limitar sus males a lo estrictamente necesario" (Truyol y Serra 1979: 52). El desarrollo de un Derecho de gentes orientado, no ya al establecimiento de las condiciones para una guerra justa, sino a la promoción de la paz, tiene importantes antecedentes en la tradición del Iusnaturalismo moderno (vid. Caranti 2017: 111ss.; Truyol y Serra 1996: 19ss.; Hermosa Andújar 2017: 34s.).
} 
fin, que sea firme y durable para impedir que los miembros se desvinculen de la misma a su voluntad en cuanto crean que su interés particular es contrario al interés general. He aquí los signos ciertos en los que se reconoce que la institución es sabia, útil e inquebrantable (Rousseau 2006, RPP: 28s.).

Como se indica en este pasaje, resulta necesario transformar la asociación espontánea de los pueblos europeos en una asociación estable, regulada por normas jurídicas que permitan prevenir la guerra y potenciar las ventajas de la unión federativa, la cual tendrá por objeto, no solo evitar los conflictos, sino además obligar a las partes asociadas a que contribuyan al bien común -del mismo modo que, en el ámbito del Derecho político, los individuos que celebran el contrato consienten subordinar su interés particular al interés general-. Ahora bien, la eficacia de la confederación dependerá de que ella concentre la fuerza necesaria para obligar a todos los Estados europeos a sumarse a ella, ya que, si no pudiese constituirse como una asociación verdaderamente general, se hallaría constantemente amenazada por las potencias que decidiesen permanecer al margen. Otra de las condiciones requeridas para su eficacia será la institución de un tribunal común, respaldado por un poder autorizado para obligar a las potencias confederadas a acatar sus dictámenes, bajo pena de coacción ${ }^{7}$. Este poder supraestatal impediría que los Estados incumplan los compromisos asumidos y evitaría que abandonen la federación toda vez que les resultara conveniente.

La propuesta rousseuaniana para la paz perpetua establece así la necesidad de erigir un poder coactivo, capaz de obligar a las naciones a unirse a la confederación, a acatar las decisiones del tribunal común, y a permanecer en la confederación más allá de sus intereses y conveniencias circunstanciales. El argumento que justifica la necesidad de un poder supraestatal autorizado para ejercer medidas coercitivas replica, en cierto modo, la célebre fórmula hobbesiana: "covenants, without the sword, are but words...". La premisa básica del argumento es que las normas instituidas para una regulación jurídica de las relaciones internacionales carecerán de fuerza vinculante mientras no se instituya un poder que pueda ejercer legítimamente la coacción contra el Estado que las incumpla; este argumento, usualmente invocado por los contractualistas modernos en su tratamiento del Derecho político, se replica así, en la propuesta rousseauniana, en el plano del Derecho de gentes.

En cuanto a la viabilidad de dicha propuesta, Rousseau señala que los príncipes le darán una acogida favorable en virtud de sus ventajas, de suyo

\footnotetext{
${ }^{7}$ Los soberanos establecerán "una alianza perpetua e irrevocable", y con este fin, "nombrarán delegados para la constitución de una asamblea permanente, la cual decidirá, en caso conflicto, por vía de arbitraje [...] y aquella potencia que se niegue a acatar los dictámenes de la asamblea será considerada como enemigo público; lo mismo ocurrirá en el caso de potencias que celebren negociaciones o tratados contrarios a los intereses de la confederación, o que inicien preparativos para la guerra" (Rousseau 2006, RPP: 29-30).
} 
evidentes: una vez establecida la confederación europea, no tendrán motivos ya para defender sus pretensiones mediante las armas; los soberanos no se verán ya en la situación de tener que empobrecer o endeudar el Estado a causa de las constantes guerras - o de los preparativos para ella-; no verán su nación debilitada ni su población mermada, y gozarán de una estabilidad que hasta el momento desconocen; finalmente, a través de la institución de un tribunal común, podrán garantizar sus derechos y posesiones, protegiéndose tanto de posibles ataques externos como de rebeliones internas ${ }^{8}$.

Es importante notar que, al señalar estos beneficios, Rousseau aclara que no apelará a los argumentos "morales" invocados en el proyecto del Abate:

Yo no osaré responder con el abate Saint-Pierre: que la verdadera gloria de los príncipes consiste en procurar la utilidad pública y la felicidad de sus súbditos; que todos sus intereses se subordinan a su reputación; y que la reputación que se obtiene entre los sabios se mide por el bien que se hace a los hombres; que, siendo la empresa de una paz perpetua la más grande jamás realizada, es la más capaz de cubrir de gloria inmortal a su autor; que, siendo esta misma empresa la más útil para los pueblos, es también la más honorable para los soberanos: es, sobre todo, la única que no se manchará de sangre, de rapiñas, de lágrimas y de maldiciones; $y$, en fin, que el medio más sensato para distinguirse entre la muchedumbre de reyes es trabajar en la felicidad pública. En los gabinetes de los ministros han ridiculizado al autor de este discurso y de este proyecto; pero no menospreciemos sus razones como ellos; y sean como fueren las virtudes de los príncipes, hablemos de sus intereses (Rousseau 2006, RPP, p. 34).

Estas observaciones dejan entrever el tono pragmático asumido por Rousseau en su proyecto para la paz perpetua. Si bien resulta evidente que la guerra, como tal, es éticamente condenable, el autor considera que resaltar las ventajas políticas y económicas de una confederación internacional resultará más eficaz al momento de persuadir a los príncipes, usualmente cegados por la ambición y el afán de poder ${ }^{9}$. El énfasis en los beneficios que conlleva la creación de una confederación de pueblos europeos no significa, sin embargo, que Rousseau desestime los argumentos morales en favor de la paz: si decide apelar a argumentos de carácter pragmático, es quizás porque advierte el escepticismo que ha despertado el proyecto del Abate entre sus contemporáneos ${ }^{10}$, y se

\footnotetext{
${ }^{8}$ Como señala Truyol, Rousseau advierte la íntima conexión existente entre la política interna y la política externa de los Estados, "y este vínculo se establece en el sentido de una primacía de la política exterior sobre la interior, que la posteridad ha venido consolidando" (Truyol y Serra 1979: 52s.).

${ }^{9}$ Granja Castro \& Charpenel Elorduy observan que Rousseau "se dirige directamente a los gobernantes, tratando de aconsejarlos en su ejercicio político. Sus destinatarios son principalmente los hombres de poder y Rousseau busca ocupar, por así decirlo, el lugar del consejero político, desalentándolos a que se entreguen a sus más ambiciosos proyectos" (Granja Castro \& Charpenel Elorduy 2014: 48).

${ }^{10}$ Como ejemplo paradigmático de esta actitud escéptica cabe recordar las palabras de Federico II de Prusia, el Principie Ilustrado, quien dirigiéndose en una carta a Voltaire escribe, respecto de
} 
anticipa, en cierto modo, a las objeciones y resistencias que su propia propuesta provocará entre los príncipes $^{11}$. Los gobernantes sensatos -argumenta- no tendrán dificultad en reconocer que las ventajas de una unión federativa superan ampliamente las desventajas que ella podría ocasionar: las restricciones a las que deberían someterse los Estados confederados suponen, en efecto, un costo menor en relación con los beneficios económicos y políticos de una asociación federativa.

Pasemos ahora a tratar el problema de cómo compatibilizar la subordinación de los Estados a un poder coercitivo supranacional con el principio de soberanía estatal. La solución sugerida por Rousseau invoca una fórmula que replica en su tratamiento del Derecho político: la libertad individual puede ser conciliada con la sujeción a la ley en la medida en que cada uno de los contratantes delegue su poder individual a fin de constituir un poder colectivo, al que se subordinará en calidad de súbdito, conservando, sin embargo, su condición de soberano. Como miembro del poder soberano, el individuo se dicta a sí mismo las leyes que han de regular su conducta: de este modo, la sujeción a la ley pública (ley que cada uno se impone a sí mismo, y de la que puede considerarse coautor) no limita la libertad individual, sino por el contrario, la hace posible ${ }^{12}$. De manera análoga,

la propuesta del Abate: "El abate Saint-Pierre me ha enviado un hermoso escrito sobre el modo de restablecer la paz en Europa y de consolidarla para siempre. La cosa es muy practicable [...]. Para hacerla triunfar solo falta el consentimiento de los europeos y algunas otras bagatelas por el estilo" (citado en: Rubio Carracedo 1998: 151).

${ }^{11}$ Diversos intérpretes destacan la perspectiva pragmática o realista a partir de la cual se desarrolla la argumentación rousseauniana en favor de una confederación para la paz. Granja Castro \& Charpenel Elorduy observan que "llama la atención que Rousseau no apoye estos planteamientos con argumentos morales. Sólo las razones pragmáticas tienen un peso en su exposición para motivar a los poderosos a que transiten hacia una alianza pacífica" (Granja Castro \& Charpenel Elorduy 2014: 48). Rubio Carracedo califica de pesimista y escéptica la posición rousseauniana respecto del problema de las relaciones interestatales (Rubio Carracedo 1998: 157s.). Truyol y Serra coincide en que las reflexiones de Rousseau dejan entrever una concepción pesimista de la relación entre los Estados; de allí que el problema requiera de una solución radical, a saber: una asociación sujeta a un poder coercitivo supraestatal (Truyol y Serra 1979: 51). Si bien coincidimos con los autores mencionados en que la argumentación de Rousseau asume un tono eminentemente pragmático, lo cierto es que la perspectiva moral no se halla del todo ausente en su discusión del problema. Hoffmann señala, acertadamente, que, tanto en su tratamiento del Derecho político como en su discusión del Derecho de gentes, el pensador ginebrino articula una perspectiva empírica (o realista) con una perspectiva normativa (Hoffmann 1963: 17). Las palabras iniciales de El contrato social revelan, en efecto, cierta intención de conjugar ambas perspectivas (en ese caso, en el tratamiento del Derecho político): "Quiero averiguar si, en el orden civil, tomando a los hombres como son y las leyes como pueden ser, puede existir alguna regla de administración legítima y segura. Intentaré siempre unir en esta investigación lo que permite el derecho con lo que prescribe el interés, a fin de que la justicia y la utilidad no estén divididas" (Rousseau 2017, CS: 5).

${ }^{12}$ A través de "la enajenación total de cada asociado con todos sus derechos a toda la comunidad", cada uno queda exento de toda sujeción a un poder arbitrario: "dándose cada uno a todos no se da a nadie, y como no hay ningún asociado sobre el cual no se adquiera el mismo derecho que se le cede sobre uno, se gana el equivalente de todo lo que se pierde y más fuerza para conservar lo que se tiene" (Rousseau 2017, CS: 19). Más adelante añade que "cada individuo, contratando, por así decirlo, consigo mismo, se encuentra comprometido por una doble relación: como miembro del Soberano hacia los particulares y como miembro del Estado hacia el Soberano" (Rousseau 2017, 
en el plano del Derecho internacional, los Estados deberían someterse a un tribunal común, conservando, sin embargo, su condición de Estados soberanos. La sujeción voluntaria a las leyes internacionales $-\mathrm{y}$ al poder supraestatal instituido para garantizar su cumplimiento- no atentará contra la autonomía e independencia de los Estados confederados, sino les permitirá reasegurar sus derechos fundamentales, liberándolos de la sujeción a poderes arbitrarios:

es mucha la diferencia que hay entre depender de otro o solo de un cuerpo del que se es miembro y del que cada cual es, a su vez, jefe; porque en el segundo caso solamente se asegura la libertad mediante las garantías que se le ofrecen; ésta se enajenaría en las manos de un amo, pero se reafirma en las de los asociados (Rousseau RPP, p. 37).

En síntesis, el mecanismo que permitiría a los Estados confederados preservar su soberanía estaría dado por su doble condición de súbditos y soberanos, es decir, por su sujeción a normas cuyo origen no es otro que la voluntad común del cuerpo colectivo. El principio de autogobierno permite así, cuanto menos en el plano formal, reasegurar la soberanía individual en el marco de la sujeción a un sistema legal: en la medida en que los Estados confederados establezcan, de manera consensuada, las normas que regularán sus relaciones recíprocas, la subordinación a tales normas no comprometerá su libertad y autonomía. Tales normas serán oportunamente establecidas a través de representantes designados para participar de la Asamblea, procedimiento mediante el cual se asegurará que ellas no contravengan lo establecido por la legislación interna de los Estados confederados. De este modo, la institución de una confederación internacional no comprometerá la soberanía estatal, más aún: permitirá a los Estados reasegurar su constitución interna frente a posibles enemigos, externos e internos.

El punto que interesa destacar aquí es que, a fin de garantizar la eficacia de las normas que han de regular las relaciones entre los Estados, Rousseau considera necesaria la institución de un poder coactivo, autorizado para forzar a las naciones a integrar la confederación, a acatar las decisiones del tribunal designado para expedirse acerca de los conflictos y, finalmente, a permanecer en la asociación, en el presunto caso de que ciertos Estados se viesen tentados a abandonar la asociación, en función de intereses particulares. Sin la existencia de un poder supraestatal, no sería posible el estado de derecho público en el ámbito de las relaciones internacionales. En la sección siguiente haremos

CS: 21). Concebida la libertad civil como "la obediencia a la ley que nos hemos prescrito" (Rousseau 2017, CS: 24), es posible articular la libertad con la sujeción legal, garantizando la convivencia pacífica. Una fórmula análoga será invocada por Rousseau a fin de resolver, en el ámbito del Derecho de gentes, el problema de la articulación entre el principio de soberanía estatal y la existencia de una confederación de Estados regulada por leyes coercitivas (Truyol y Serra 1979: 56). A esta cuestión haremos mayor referencia en las secciones siguientes. 
referencia a la propuesta kantiana, y procuraremos exponer los motivos por los que Kant rechazaría la solución sugerida por Rousseau.

\section{Kant y el proyecto de una confederación de Estados libres orientada a la paz perpetua}

En Hacia la paz perpetua, Kant declara que, mientras las naciones resuelvan sus pretensiones de derecho a través de la guerra -y su resultado: la victoria-, no podrá garantizarse la justicia en el ámbito de las relaciones internacionales. En este escrito propone -emulando el modo en el que se redactaban, en la época, los tratados de paz- una serie de Artículos preliminares y Artículos definitivos, cuyo propósito es, en términos generales, explicitar las condiciones para la consolidación de un Derecho de gentes, que pueda contribuir de manera efectiva a la resolución pacífica de los conflictos entre las naciones. En algunos de los Artículos preliminares (aquellos que hacen referencia a estrategias o acciones que, realizadas en el contexto de una guerra, tornarían imposible la paz futura $)^{13}$, Kant invoca el principio de soberanía estatal, en virtud del cual todo Estado debe ser reconocido como persona moral ${ }^{14}$. Apelando a dicho principio, el Quinto artículo preliminar establece que "ningún Estado debe inmiscuirse por la fuerza en la constitución o el gobierno de otro" (Kant 2007, ZeF, Ak. VIII: 345). Si un Estado atraviesa una situación de conflicto interno, ello no autoriza a otros Estados a intervenir para poner orden a la situación, pues la falta de legalidad al interior de un Estado no supone, en rigor, lesión alguna para otros Estados. Kant aclara, sin embargo, que en caso de que el conflicto interno llegara al extremo de provocar la escisión de un Estado (y su consiguiente transformación en dos o más Estados independientes), auxiliar a una de las partes en conflicto no implicaría intervenir ya en su constitución interna, pues en tal situación se habría disuelto ya el Estado. Más allá de esa excepción, el filósofo rechaza el principio de intervención estatal, declarándolo contrario al derecho de los Estados: "la injerencia de potencias exteriores supondría la violación

13 Si bien algunos comentaristas reprochan a Kant el haber incluido, en los Artículos preliminares, algunas cláusulas orientadas en la línea de las doctrinas de la guerra justa (Bories 1973: 223), otros consideran al filósofo como un crítico de tales doctrinas (Tomassini 2018: 423ss.); y hay quienes señalan, por su parte, que la inclusión de tales cláusulas responde a la intención de promover una suerte de humanización de los conflictos bélicos, en vistas a la paz futura (Contreras Peláez 2007: 117-119; Santiago 2004: 130).

14 En La metafísica de las costumbres, Kant declara que no son lícitas las guerras punitivas ni las guerras de exterminio, ya que, además de atentar contra la paz futura, suponen la aniquilación del Estado como persona moral (Kant 1994, MS, Ak. VI: 347). Podría afirmarse, a partir de esta caracterización del Estado como persona, que el "correlato jurídico" de la autonomía (como condición inherente a la persona) está dado, en el caso del Estado, por la soberanía. 
de los derechos de un pueblo independiente que se debate con su propia enfermedad" (Kant 2007, ZeF, Ak. VIII: 346) ${ }^{15}$.

En cuanto al alcance de los Artículos preliminares, Kant establece, en el sexto artículo, que aún en el actual estado de naturaleza internacional los pueblos no deben recurrir a estrategias que pudiesen imposibilitar la paz futura; sin embargo, es consciente de que recomendaciones prudenciales de este tipo no resultan suficientes para garantizar la paz. De allí que el Derecho de gentes no pueda limitarse a establecer normas para una guerra justa, sino que deba plasmarse en instituciones que tengan como propósito promover una paz duradera y estable, la paz perpetua. La propuesta kantiana, orientada a la creación de una confederación de Estados libres, se presenta, según veremos, como una propuesta amparada, no ya en propósitos pragmáticos, sino en principios jurídicos fundados en la razón. Kant sostiene, en efecto, que la razón, en su uso práctico, prescribe abandonar ese estado en el que no pueden ser garantizados los derechos inherentes al ser humano, y exige ingresar en un estado en el que los conflictos puedan ser dirimidos sin recurrir a la violencia:

Según la razón, los Estados con relaciones recíprocas no tienen más remedio que salir del estado sin leyes que solo entraña la guerra, tal como los individuos abandonan su salvaje libertad sin ley, y amoldarse a restrictivas leyes públicas configurando un Estado de pueblos que crezca constantemente hasta abarcar finalmente a todos los pueblos de la tierra (Kant 2007, ZeF, Ak. VIIII: 357).

El Segundo artículo definitivo para la paz perpetua establece que "el derecho de gentes debe sustentarse en un federalismo de Estados libres" (Kant 2007, ZeF, Ak. VIII: 354). En vistas de los riesgos que conllevaría la institución de una República mundial, la solución alternativa consiste en una asociación federativa no sujeta a un poder coactivo común, asociación que los Estados deberán integrar de manera voluntaria ${ }^{16}$.

Ahora bien, en uno de los Artículos definitivos para la paz perpetua, Kant sostiene que si un individuo (o un pueblo) decidiese permanecer en estado de naturaleza, podría ser obligado a ingresar en el estado civil, ya que su sola proximidad supondría para otros individuos (u otros pueblos) una amenaza constante:

\footnotetext{
${ }^{15}$ El principio de no intervención se funda en la validez incondicionada del principio de soberanía estatal, principio que Kant reivindicará de manera explícita, según veremos, al rechazar la República mundial como solución al problema de los conflictos interestatales. Sobre esta cuestión, vid. Santiago 2004: 148s.

${ }^{16}$ Como señala Lutz-Bachmann, Kant considera que la institución de una República mundial implicaría la disolución de los Estados soberanos y de su constitución interna (Lutz-Bachmann 1997: 70-74). Al respecto observa Llano Alonso: "Kant no pretendía la creación de un macro-Estado mundial, sino una federación de Estados de Derecho libres entre las distintas naciones del mundo, de tal manera que ninguna de ellas terminara subyugando a las demás. Lo contrario, es decir, la constitución de un gobierno mundial único, podría terminar degenerando en un despotismo universal o, expresado con las palabras del propio Kant, en el cementerio de la libertad"' (Llano Alonso 2012: 217).
} 
el ser humano -o el pueblo- inmerso en el estado de naturaleza me priva de esa seguridad y me causa ya un perjuicio por el mero hecho de hallarse junto a mí en ese estado, aunque no lo haga de facto sino por la constante amenaza que supone para mí la carencia de leyes de su estado, que al no tenerlas es injusto, por lo cual puedo obligarle a ingresar conmigo en un estado de comunidad legal o a que no siga colindando conmigo. Así las cosas, el postulado que subyace a los siguientes artículos es «que todos los seres humanos que puedan tener una influencia recíproca han de pertenecer a algún tipo de constitución civil» (Kant 2007, ZeF, Ak. VIII: 349) ${ }^{17}$.

La interpretación de este pasaje presenta algunas dificultades. En primer lugar, debe considerarse en qué sentido se afirma aquí que la decisión de un Estado de permanecer en estado de naturaleza es injusta. Desde la perspectiva kantiana, es injusto aquello que viola una norma establecida (entendida como norma cuyo propósito es garantizar un derecho); sin embargo, en el estado de naturaleza no rigen leyes públicas, con lo cual no podría darse en él, en sentido estricto, injusticia alguna. ¿Cómo interpretar, entonces, la tesis que afirma que la permanencia en el estado de naturaleza es injusta? En segundo lugar, se indica en el pasaje citado que un individuo o pueblo que decidiese permanecer, junto a otros, en estado de naturaleza, causaría a éstos un perjuicio en razón de su situación anómica, y por tal motivo podría ser obligado a ingresar, junto a ellos, en una asociación civil. ¿Pero cómo debe entenderse esa obligación? ¿Podría acaso una confederación internacional obligar a un Estado a integrarse a ella a través de medios coercitivos? ¿Acaso no violaría con ello el principio de soberanía estatal, reivindicado explícitamente por Kant en los Artículos preliminares?

En cuanto a la primera dificultad -referida a la injusticia que supondría la permanencia de un Estado o pueblo en el estado de naturaleza-, se ha indicado ya que, desde la perspectiva kantiana, puede calificarse injusto a aquello que viola una norma o un derecho. Ahora bien, ¿qué derecho violaría tal permanencia? ¿Acaso cabría considerar la paz como un derecho de los Estados (derecho que pudiese invocarse a fin de calificar injusta la resistencia de un pueblo a ingresar en un estado de derecho público internacional)? ¿Cabría afirmar que un Estado que se negara a integrar la confederación de pueblos estaría violando un derecho de otros Estados, a saber: su derecho a la paz? Si ese fuera el caso, un Estado podría legítimamente forzar a otros Estados a sujetarse a las normas del Derecho de gentes, a los fines de garantizar ese, su derecho a la paz.

\footnotetext{
${ }^{17}$ Más adelante añade: "En cuanto los Estados o pueblos pueden considerarse como individuos que se perjudican mutuamente por su mera vecindad en el estado de naturaleza, es decir, al margen de leyes externas, y en aras de su propia seguridad, cada cual debe y puede reclamar a otro que ingrese junto a él en una constitución similar a la civil, donde cada uno pueda ver asegurado su derecho" (Kant 2007, ZeF, Ak. VIII: 354).
} 
Considero que, en el marco de la metafísica jurídica kantiana, la paz es una exigencia de la razón práctica, un mandato moralmente vinculante para todo sujeto racional, un fin al que necesariamente debemos orientarnos ${ }^{18}$. Pero no por ello puede afirmarse que la paz sea un derecho. En efecto, no hay un derecho natural de los Estados (entre los cuales podría incluirse ese presunto derecho a la paz), ni tampoco podría considerarse la paz como un derecho positivo, pues toda norma positiva presupone la institución de un poder coactivo que garantice su cumplimiento, pero esto es, precisamente, lo que no se ha dado (ni debería darse, desde la perspectiva asumida por Kant) en el ámbito de las relaciones internacionales. ¿En qué sentido, entonces, puede declarar Kant injusta la permanencia de un pueblo en el estado de naturaleza?

En el $\$ 54$ de La metafísica de las costumbres hallamos algunas observaciones que pueden ser relevantes para dar respuesta a ese interrogante. Allí el filósofo caracteriza el estado no jurídico en las relaciones interestatales como un estado de guerra (no necesariamente como estado de guerra efectiva, sino antes bien como estado en el que se da una constante amenaza de guerra), y lo describe a continuación como un estado de naturaleza, en el que solo puede regir el derecho del más fuerte. Declara allí que la constante posibilidad de la guerra es "injusta en grado sumo" [im höchsten Grade unrecht], por cuanto torna imposible garantizar los derechos de los miembros de un Estado (Kant 1994, MS, Ak. VI: 344) ${ }^{19}$. Esto significa que la justicia solo es posible en un marco legal, i.e. solo puede darse bajo la condición de la existencia de leyes públicas, y esto rige tanto para las relaciones entre individuos como para las relaciones entre Estados -es decir, tanto para el ámbito del Derecho político como para el ámbito del Derecho de gentes- ${ }^{20}$. Así como no puede haber

${ }^{18}$ Como señala Truyol y Serra, "la misma exigencia racional del imperativo categórico que obliga a los individuos a asociarse en el Estado, les obliga también a superar el estado de naturaleza que impera entre los Estados y constituir una unión de Estados (Staatenverein) o Estado de los pueblos (Völkerstaat, civitas gentium)" (Truyol y Serra 1979: 57).

${ }^{19}$ El estado de naturaleza no es, en sí mismo, injusto; sin embargo, al no haber, en tal estado, un juez competente autorizado para dirimir los conflictos, el derecho de cada uno solo puede resolverse a través de la fuerza, y resulta así carente de garantías. Tal como se afirma en La metafísica de las costumbres, el estado de naturaleza es un estado sin derecho (Kant 1994, MS, Ak. VI: 312), y en tal sentido cabe considerarlo injusto. Lo injusto, en rigor, es permanecer en semejante estado: "Mientras pretenden estar y permanecer en este estado de libertad exterior sin ley, los hombres no son injustos en modo alguno unos con otros si luchan entre sí, porque lo que vale para uno vale también recíprocamente para el otro, como en un convenio [...]; pero en realidad son injustos en sumo grado al querer estar y permanecer en un estado que no es jurídico, es decir, un estado en que nadie está seguro de los suyo frente a la violencia” (Kant 1994, MS, Ak. VI: 307-308).

${ }^{20}$ Cabe señalar que el proyecto kantiano para la paz perpetua no se agota en la institución y consolidación de un Derecho de gentes, sino que requiere asimismo de un Derecho cosmopolita. Para un análisis pormenorizado de la reflexión kantiana acerca del cosmopolitismo, y su relación con la cuestión de la paz, vid. Byrd \& Hruschka 2010: 205ss. Un interesante estudio acerca de las premisas bajo las cuales Kant aborda la cuestión del Derecho cosmopolita y, en general, la cuestión de la fundamentación de los derechos humanos, puede hallarse en: Sánchez Madrid 2016: 191-206. 
derecho estricto sino en el marco de una constitución civil (Kant 1994, MS, Ak. VI: 232), así tampoco es posible, en el ámbito de las relaciones internacionales, garantizar el ejercicio de los derechos, ni por tanto la justicia, sin la sujeción de los pueblos a leyes públicas internacionales. Por consiguiente, aun cuando los individuos (o pueblos) que no han ingresado en un estado de derecho público no se hallen sujetos a normas jurídicas $-\mathrm{y}$ por tanto sus acciones no puedan declararse injustas en el sentido de que violen leyes positivas-, la permanencia en el estado de naturaleza es injusta en tanto supone la permanencia voluntaria en un estado en el que ninguna justicia es posible, un estado en el que ningún derecho puede ser efectivamente garantizado. En síntesis: la permanencia en el estado natural es contraria a la justicia en el sentido de que impide asegurar las condiciones bajo las cuales pueden ser ejercidos los derechos en general.

Se ha sugerido que la paz no puede ser considerada, en rigor, como un derecho de las naciones. Cabría añadir que la promoción de la paz no es una obligación jurídica, cuyo incumplimiento por parte de un Estado pudiese autorizar a otros Estados a ejercer la coacción contra aquél. Sin embargo, promover la paz es un mandato práctico, un deber moral; y esto es, precisamente, aquello que permite desestimar cualquier consideración escéptica referida a la factibilidad del proyecto para la paz perpetua: aun cuando se presentaran incontables obstáculos para su realización, este mandato no perdería carácter vinculante $^{21}$. La razón práctica prescribe promover la paz y redoblar los esfuerzos para la consolidación de instituciones orientadas a una regulación jurídica de las relaciones internacionales. Ahora bien, si la promoción de la paz es un deber, los deberes morales no son vinculantes del mismo modo en que lo son los deberes jurídicos. La decisión -de un individuo o de un pueblo- de permanecer en estado de naturaleza -como decisión que viola, no una norma jurídica, sino únicamente un precepto moral-, no autoriza a otros individuos o pueblos a emplear la coacción para forzar el ingreso en el estado jurídico.

\footnotetext{
21 “Ahora bien, la razón práctico-moral expresa en nosotros su veto irrevocable: no debe haber guerra; ni guerra entre tú y yo en el estado de naturaleza, ni guerra entre nosotros como Estados que, aunque se encuentren internamente en un estado legal, sin embargo, exteriormente (en su relación mutua) se encuentran en un estado sin ley; porque este no es el modo en que cada uno debe procurar su derecho. Por lo tanto, la cuestión no es ya la de saber si la paz perpetua es algo o es un absurdo, y si nos engañamos en nuestro juicio teórico si suponemos lo primero; sino que hemos de actuar con vistas a su establecimiento [...] y acabar con la terrible guerra [...]. Y aunque esto último - lo que concierne al cumplimiento de este propósito- quedara como un deseo irrealizable, no nos engañaríamos ciertamente al aceptar la máxima de obrar continuamente en esta dirección, porque esto es un deber..." (Kant 1994, MS, Ak. VI: 334-335). Un argumento análogo es presentado, algunos años antes, en el escrito En torno al tópico: "Tal vez eso sea correcto en teoría, pero no sirve para la práctica», texto en el que Kant establece el deber moral de conservar la esperanza en el progreso del género humano (Kant 1993, TP, Ak. VIII: 308-309). Como señala Rodríguez Aramayo, la esperanza representa, en los escritos histórico-filosóficos kantianos, una suerte de correlato del deber moral (Rodríguez Aramayo 2001: 69).
} 
Arribamos con ello a la segunda dificultad mencionada, referida a la posibilidad o imposibilidad de coaccionar a un Estado a abandonar el estado de naturaleza. Si bien Kant sostiene, en el pasaje citado, que un individuo o Estado puede ser obligado a ingresar junto a otros en la asociación jurídica internacional, esto no significa que pueda ser obligado a ello de manera forzosa: semejante acción violaría, en efecto, el principio de soberanía estatal $^{22}$. Un Estado puede obligar [nöthigen] a otro a ingresar junto a él en una comunidad legal (Kant 2007, ZeF, Ak. VIII: 349) y, en pos de su seguridad, puede reclamar, exigir [fordern] a otros Estados que ingresen junto a él en una confederación (Kant 2007, ZeF, Ak. VIII: 354). Pero en todo caso lo que se invoca aquí es una obligación o exigencia de carácter moral. La razón práctica exige, obliga a la institución de un Derecho público internacional: "desde el trono del supremo poder legislativo-moral, la razón sí reprueba sin ambages la guerra como procedimiento judicial y por el contrario proclama como deber inmediato el estado de paz, que ciertamente no puede instaurarse ni asegurarse sin un pacto entre los pueblos" (Kant 2007, ZeF Ak. VIII: 356). El carácter vinculante de esa obligación (aquella que prescribe a los Estados ingresar en una comunidad jurídica internacional) no es tal que habilite a otros Estados a ejercer medios coactivos en pos de asegurar ese ingreso.

En una Reflexión datada entre 1780 y 1789, Kant observa que "los individuos in statu naturali pueden ser obligados a entrar junto con otros en un status civilis [...]. Pero los pueblos, que se encuentran ya en el estado civil, no pueden obligarse recíprocamente a aceptar un soberano común" (Kant 1902s., Refl. No 8065, Ak. XIX). Esta observación expresa, en cierto modo, los límites de la analogía entre el Derecho político y el Derecho de gentes ${ }^{23}$. Si bien el problema que en ambas instancias del Derecho público pretende resolverse resulta, hasta cierto punto, equiparable (esto es: el problema de cómo conciliar el arbitrio de cada uno con el arbitrio de otros, a través de leyes públicas), la solución adoptada en cada instancia no puede ser análoga: los individuos deben renunciar a su libertad salvaje para gozar de una libertad amparada por leyes (para lo cual resulta necesaria de la institución de un poder coactivo que garantice su cumplimiento)-, pero los Estados no pueden

${ }^{22}$ El proyecto kantiano de una comunidad jurídica internacional, tal como aparece esbozado en los textos kantianos de madurez, exige que la sujeción de los Estados a normas jurídicas internacionales no comprometa su autonomía (Williams 1983: 250). Granja Castro y Charpenel Elorduy observan que "debido a su comprensión radical de lo que es el carácter moral de un Estado, Kant desiste totalmente de proponer medidas que pongan en peligro la autonomía de un pueblo. A diferencia de la transición del estado natural hacia un estado social - en la que, según Kant, es permisible coaccionar a otros para que ingresen en ese nuevo orden político-, en el nivel supranacional no existe la posibilidad de ejercer coacción sobre otro Estado para que se afilie a una confederación de paz" (Granja Castro \& Charpenel Elorduy 2014: 56).

${ }^{23}$ Cf. Ripstein 2009: 227. Si bien Kant suele trasponer el modelo contractualista invocado en su fundamentación del Derecho político al plano del derecho internacional (Llano Alonso 2012: 215), esta trasposición tiene sus límites, por los motivos que acabamos de señalar. 
ser forzados a sujetarse a normas internacionales, pues poseen ya sus propias leyes internas ${ }^{24}$. De allí que Kant caracterice la federación para la paz como una institución que

no pretende adquirir ningún poder de tipo estatal, sino simplemente establecer y asegurar la libertad de un Estado al tiempo que hace lo propio con la de los otros Estados federados, sin que por ello deban someterse, como los individuos en el estado de naturaleza, a la coacción de leyes públicas (Kant 2007, ZeF, Ak.

VIII: 356).

Si bien la permanencia (de los individuos o de los pueblos) en un estado de naturaleza puede considerarse injusta, la solución será diversa en el caso de las relaciones entre individuos y en el caso de las relaciones entre pueblos: la confederación para la paz, tal como Kant la concibe en Hacia la paz perpetua, no exige la constitución de un Estado supranacional, sino de una asociación de Estados libres, que se sometan voluntariamente a los dictámenes de una asamblea judicial en vistas a una resolución pacífica de sus conflictos. La solución kantiana al problema de las relaciones internacionales no desatiende, pues, las diferencias insalvables entre el Derecho político y el Derecho de gentes: en esta última instancia del Derecho público no será necesario erigir un poder coercitivo común, sino únicamente se exigirá que los Estados confederados acaten las decisiones de un tribunal de justicia instituido por la confederación ${ }^{25}$.

A partir de lo expuesto, puede concluirse que, en su respuesta a los interrogantes y desafíos que plantea la consolidación del Derecho internacional, Kant prioriza el principio de soberanía estatal; de allí que se incline, en sus escritos de madurez, por una asociación de Estados libres, no sujetos a un poder coactivo supranacional ${ }^{26}$. La existencia de un poder semejante implicaría

${ }^{24}$ Byrd \& Hruschka se refieren a las diversas propuestas discutidas por Kant como posible solución al conflicto internacional. Una de ellas estaría dada por el Estado mundial o Monarquía universal (que implicaría la disolución de los Estados nacionales, solución que será rechazada por Kant en Hacia la paz perpetua); otra posibilidad estaría dada por el Estado de las naciones o República mundial (en la que los Estados asociados se someterían por igual a una legislación común y a un poder coactivo que la respalde); finalmente, una tercera posibilidad - por la que se inclina Kant en los escritos de madurez- sería la de una Liga de las naciones, no sujetas a un poder coactivo común. Si bien Kant advierte que la institución de una República mundial resultaría más efectiva a fin de asegurar la paz, se inclina sin embargo por la Liga de las naciones, considerando la idea de una República mundial como una suerte de principio regulativo (Byrd \& Hruschka 2010: 203).

${ }^{25}$ La confederación de Estados libres no se regulará por leyes internacionales establecidas por un poder legislativo (soberano), sino que su regulación requerirá únicamente de la institución de un tribunal autorizado para decidir cómo deben resolverse, en cada caso, las pretensiones de derecho (Ripstein 2009: 229s.).

${ }_{26}$ Al respecto señala Rodríguez Aramayo: "Kant apuesta por una federación de pueblos y alerta contra los peligros de una estructura macro-estatal en que se fusionaran distintos pueblos, porque a la postre se convertirían en un solo pueblo, perdiendo por tanto sus rasgos específicos" (Aramayo, 24). A las desventajas ligadas a una disolución de las particularidades culturales de las naciones se añaden, desde luego, los peligros inherentes a la constitución de un poder supra-estatal que amenazaría la soberanía de los Estados fusionados en una república única; de allí que Kant se incline por la solución de "una libre asociación federativa donde sus miembros viesen asegurada su libertad, igualdad e 
una seria amenaza para la soberanía de los Estados, principio fundamental del Derecho político. Si bien Kant sostiene que los Estados pueden y deben ser obligados a ingresar en el estado civil (así como los individuos pueden y deben serlo), el derecho de reclamar o exigir a un Estado su ingreso en una asociación jurídica internacional no implica un derecho de ejercer coacción contra él.

\section{Consideraciones finales}

El propósito de este escrito ha sido examinar las premisas a partir de las cuales se desarrollan las propuestas de solución de Rousseau y de Kant frente al problema del carácter vinculante de las normas del Derecho de gentes. Apelando a premisas que cabría calificar como pragmáticas, Rousseau declara que solo es posible garantizar la eficacia de las normas jurídicas internacionales a través de la institución de un poder coactivo supranacional. Kant, por su parte, rechaza esa solución por los riesgos que ella supone para la soberanía estatal; sin embargo, no logra resolver el problema de cómo garantizar la eficacia de las normas internacionales (por tanto, el problema de cómo garantizar la justicia), dada la ausencia de un poder autorizado para ejercer coacción contra los Estados que incumpliesen los acuerdos establecidos, o se negasen a celebrar acuerdos $^{27}$.

Rousseau no ignora, por su parte, los riesgos que conlleva la institución de un poder coactivo supranacional. En el escrito titulado Jugement sur la paix perpétuelle, luego de señalar las ventajas de una confederación internacional sujeta a un poder común ${ }^{28}$, advierte acerca de los males que podrían suscitarse en

\footnotetext{
independencia” (Aramayo 2018: 24).

${ }^{27}$ Algunos intérpretes señalan que Kant simplemente confía en un proceso de republicanización interna de los Estados, que acabaría por hacerse extensivo al ámbito de las relaciones interestatales (Höffe 2004: 116; Brandt 2004: 140-141). Señalando las insuficiencias de la solución kantiana al problema de las relaciones entre los Estados, Hermosa Andújar observa que el planteamiento kantiano de la cuestión deja sin resolver importantes interrogantes, a saber: ¿cómo podría darse ese proceso de una progresiva republicanización de los Estados? ¿Qué costos traería aparejados? ¿Sería legítimo forzar a regímenes autocráticos a adoptar una forma republicana de gobierno? ¿No requeriría acaso de innumerables enfrentamientos bélicos? Si en la filosofía práctica kantiana convergen los dominios de la moral, el derecho y la política, en el ámbito específico de las relaciones internacionales Kant no lograría garantizar esa convergencia, pues no parece aportar soluciones concretas a situaciones en las que el interés particular de los Estados supone una amenaza para la paz y para el resguardo de los derechos (Hermosa Andújar 2017: 29ss.). Así concluye el autor que el problema de la paz "no admite una única solución general deducible a priori de una razón universal" (Hermosa Andújar 2017: 47). "Son precisas, en suma, más y mejores teorías, y menos unidad sistemática entre ellas, que la preconizada por Kant para alcanzar y preservar la paz en aras de la seguridad internacional" (Hermosa Andújar 2017: 49). En otro interesante estudio señala Hermosa Andújar que el modelo de sociedad internacional propuesto por Kant exhibe una tensión básica, "aquella que se da "entre la necesidad de crear normas jurídicas internacionales vinculantes y el mantenimiento a ultranza de la plena soberanía de cada miembro asociado, tensión meramente planteada por Kant, pero no desarrollada..." (Hermosa Andújar 1989: 189).

28 "Pienso que jamás se ha demostrado mejor una verdad moral como es la utilidad general y
} 
el proceso de consolidación de las uniones federativas, que suelen organizarse a través de "medios violentos y temibles para la humanidad [...], sobre esta base ¿quién de nosotros se atreve a decir que tal Liga Europea es deseable o temible? Quizás cause de un golpe más males que los que podría prevenir durante siglos" (Rousseau 2006, JPP: 49). Estas observaciones revelan, una vez más, las premisas pragmáticas bajo las cuales el filósofo aborda los problemas referidos al Derecho de gentes: si bien el proyecto de una confederación para la paz sólo podrá imponerse a través de la fuerza, esto podrá ocasionar incluso males superiores a los bienes que traería consigo la paz.

Ajeno a las premisas pragmáticas bajo las cuales Rousseau aborda el problema de la regulación de las relaciones internacionales, Kant discute estos tópicos bajo premisas jurídicas de carácter normativo. Independientemente de las dificultades fácticas implicadas en la institución de una República mundial, el rechazo de esta solución responde ante todo a un principio jurídico, aquel que establece la soberanía estatal como fundamento último del Derecho político. Bajo una perspectiva racional, apriorística y normativa, Kant exhorta a la institución de una federación de Estados libres, y confía en la viabilidad del proyecto para la paz perpetua, así como confía en el constante progreso del género humano hacia un estado de mayor perfección, confianza asentada, en última instancia, en un deber moral ${ }^{29}$. Desde una perspectiva jurídica y moral, el autor establece el deber de promover la paz, deber que no pierde su carácter vinculante en razón de los innumerables obstáculos que indudablemente se presentarán en el proceso de consolidación de las instituciones jurídicas internacionales ${ }^{30}$. Ante el problema de un posible incumplimiento de las normas establecidas para la regulación de las relaciones entre los Estados (y dada la ausencia de una espada

particular de este Proyecto. Las ventajas que resultarían de su ejecución [refiriéndose a la ejecución del proyecto del Abate de Saint-Pierre], tanto para cada príncipe como para cada pueblo y para toda Europa, son inmensas, claras, incontestables" (Rousseau 2006, JPP: 42).

${ }^{29} \mathrm{Cf}$. supra, nota 21. La reflexión kantiana en torno al Derecho de gentes se articula así con una concepción del progreso desarrollada en el marco de una filosofía de la historia que asume un claro sentido normativo (Truyol y Serra 1997: 61; Brandt 1996: 33; Kersting 1992; Beade 2014; Beade 2016). Como señala Hermosa Andújar, en la filosofía práctica kantiana el Derecho político confluye naturalmente en el Derecho de gentes y en un Derecho cosmopolita, complementos fundamentales e indispensables de aquél, de tal modo que la paz será "el efecto de la acción concordante de las tres ramas del derecho público" (Hermosa Andújar 2017: 40). Para fundamentar esta concordancia Kant recurre a una filosofía de la historia basada en la idea de una naturaleza garante del progreso histórico, apela a la razón como aquella facultad que deberá producir efectos en el desarrollo histórico, y destaca la labor indispensable del filósofo en este proceso, asignándole la ineludible tarea de interpretar y reivindicar los derechos inherentes al ser humano (Hermosa Andújar 2017: 40-41).

${ }^{30}$ Kaufman observa que el realismo escéptico rousseauniano prima al momento de optar por una federación de Estados europeos sujeta a un poder coactivo; en contraposición, el optimismo de Kant, fundado en la matriz práctica y normativa que modela sus reflexiones políticas, lo lleva a inclinarse por un federalismo de Estados libres (Kaufman 1997: 25ss.). En esta misma línea de interpretación, Villegas vincula las soluciones propuestas por Rousseau y Kant al problema de la paz con sus respectivas premisas antropológicas, y contrapone (al igual que Kaufman) el pesimismo antropológico rousseuaniano al optimismo normativo kantiano (Villegas 2015: 30ss.). 
que garantice la observancia de los compromisos asumidos), Kant simplemente confía en el progresivo avance del republicanismo, tanto en el ámbito interno como en el externo ${ }^{31}$. Esta confianza en el progreso de las instituciones políticojurídicas expresa, en última instancia, una confianza en el progreso de la razón misma, de la Ilustración, progreso que podrá detenerse, interrumpirse, pero que acabará por conducirnos a una consolidación gradual del republicanismo, del Derecho de gentes y del Derecho cosmopolita (Kant 2007, ZeF, Ak. VIII: 360ss. $)^{32}$.

La regulación jurídica de la comunidad internacional puede ser concebida, en síntesis, como un fin, un ideal regulativo, una meta cuya realización progresiva requerirá de una revisión constante de los medios que puedan propiciarla, conforme a las exigencias de la cambiante realidad política, económica y jurídica de los Estados. Ahora bien, asumir la paz como fin -y aquí reside quizás la principal dificultad, o el mayor desafío- parece exigir la construcción de consensos acerca del derecho y la justicia. En tal sentido la reflexión filosófico-política deberá necesariamente acompañar el proceso de desarrollo de los medios y estrategias conducentes a la paz, contribuyendo, a través de esa labor teórica, a su posible realización.

\footnotetext{
${ }^{31}$ A propósito de este punto, observa Truyol y Serra: "Así como Rousseau ponía en duda el que la unión de los Estados en una sociedad civil mundial (incluso en una sociedad civil europea) fuese factible, también Kant se hace cuestión de la posibilidad de instaurar el Estado universal, y con él la paz perpetua [...]. Pero su actitud [...] es típica de todo su modo de pensar. Aunque no sea posible la realización del Estado universal, y con él la de la paz perpetua, lo que sí es realizable en todo caso es la aproximación al mismo mediante el adecuado proceso de asociación de los Estados" (Truyol 1979: 59). Más adelante añade: "a diferencia de lo que ocurriera en Rousseau, la incertidumbre que pueda abrigar el pensamiento acerca del futuro viable queda finalmente superada en Kant por la historia. Porque a través de un largo proceso, la propia naturaleza conduce la humanidad al Estado mundial. Y lo hace, con un superior designio, aprovechando no sólo las solidaridades, sino también las rivalidades y luchas" (Truyol y Serra 1979: 61).

32 La perspectiva normativa es, quizás, la única respuesta posible para Kant (tal vez insuficiente) ante los obstáculos que supone la realización empírica del ideal de la paz perpetua, entendida como el bien político supremo (Kant 1994: MS, Ak. VI, 355). Kant sostiene que es posible -más aún: necesario- asumir la paz como un fin, y en 6tal sentido la caracteriza como "la totalidad del fin final de la doctrina del derecho, dentro de los límites de la mera razón” (Kant 1994, MS, Ak. VI: 355). "Y aunque esto último -lo que concierne al cumplimiento de este propósito- quedara como un deseo irrealizable, no nos engañaríamos ciertamente al aceptar la máxima de obrar continuamente en esta dirección; porque esto es un deber..." (Kant 1994, MS, Ak. VI: 354-355). Esta máxima se funda en la razón práctica, que "expresa en nosotros su veto irrevocable: no debe haber guerra [...] porque éste no es el modo en que cada uno debe procurar su derecho. Por lo tanto, la cuestión no es ya la de saber si la paz perpetua es algo o es un absurdo, y si nos engañamos en nuestro juicio teórico si suponemos lo primero; sino que hemos de actuar en vistas a su establecimiento [...] Y aunque esto último -lo que concierne al cumplimiento de este propósito- quedara como un deseo irrealizable, no nos engañaríamos ciertamente al aceptar la máxima de obrar continuamente en esta dirección, porque esto es un deber"' (Kant 1994, MS, Ak. VI: 354).
} 


\section{Bibliografía:}

Apel, K. (1997), “Kant's 'Toward Perpetual Peace' as Historical Prognosis from the Point of View of Moral Duty", en: J. Bohman \& M. LutzBachmann (eds.), Perpetual Peace. Essays On Kant's Cosmopolitan Ideal, Massachusetts, MIT Press.

Beade, I. (2016), "Some Remarks on Kant's Concept of an a priori History", Studia Kantiana, 22, pp. 71- 84

Beade, I. (2014), "Acerca del carácter regulativo de las ideas de la razón en el marco de la doctrina jurídico-política kantiana", Revista Portuguesa de Filosofía, 70, 2, pp. 473-492. http://dx.doi.org/10.17990/ RPF/2014 $70 \quad 20473$ [28/01/21].

Bories, K. (1973), Kant als Politiker. Zur Staats- und Gesellschatslehre des Kritizismus, Hamburg, Scientia Verlag Aalen.

Brandt, R. (1996), "Observaciones crítico-históricas al escrito de Kant sobre la paz”, en: R. Rodríguez Aramayo, J. Muguerza y C. Roldán (eds.), La paz y el ideal cosmopolita de la Ilustración. A propósito del bicentenario de Hacia la paz perpetua de Kant, Madrid, Tecnos, pp. 31-64.

Brandt, R. (2004), "Vom Weltbürgerrecht”, en: O. Höffe (ed.), Immanuel Kant. Zum ewigen Frieden (pp. 109-132), Berlin, Akademie Verlag GmbH, pp. 133-149.

Höffe, O. (2004), “Völkerbund oder Weltrepublick?”, en: O. Höffe (ed.), Immanuel Kant. Zum ewigen Frieden, Berlin, Akademie Verlag $\mathrm{GmbH}$, pp. 109-132.

Byrd, S. \& Hruschka, J. (2010), Kant's Doctrine of Right. A Commentary, New York, Cambridge University Press.

Caranti, L. (2017), Kant's Political Legacy. Human Rights, Peace, Progress. Wales, United Kingdom, University of Wales Press.

Contreras Peláez, F. J. (2007), Kant y la guerra. Una revisión de La Paz Perpetua desde las preguntas actuales, Valencia, Tirant Lo Blanch.

Espinosa Antón, F. (2014), "Los proyectos de paz y el cosmopolitismo en la Ilustración", Araucaria. Revista Iberoamericana de Filosofía, Política y Humanidades, 16, 32, pp. 5-23.

Fetscher, I. (1979), "Filosofía moral y política en J. J. Rousseau", Revista de Estudios Políticos, 8, 1979, pp. 7-32

Granja Castro, D. M. \& Charpenel Elorduy, E. (2014), "El ideal de la paz perpetua en Rousseau y Kant", Signos Filosóficos, XVI, 31, pp. 37-62.

Habermas, J. (1997), "Kant's Idea of Perpetual Peace, with the Benefit of Two Hundred Years'Hindsight", en: J. Bohman \& M. Lutz-Bachmann (eds.), Perpetual Peace. Essays On Kant's Cosmopolitan Ideal, Massachusetts, MIT Press, pp. 113-153. 
Hermosa Andújar, A. (1989), "La concepción kantiana de las relaciones internacionales", Revista de Estudios Politicos, 64, pp. 163-189.

Hermosa Andújar, A. (2017), "El problema de la paz en Kant", Ius. Revista del Instituto de Ciencias Jurídicas de Puebla, México, 11, 40, 2017, pp. 29-50.

Hobbes, T. (1996), Leviatán, o la materia, forma y poder de una república eclesiástica y civil [Leviathan, or the Matter, Forme, and Power of a Commonwealth, Ecclesiasticall and Civil, 1651], traducción de M. Sánchez Sarto, México, Fondo de Cultura Económica.

Hoffmann, S. (1963), "Rousseau on War and Peace", American Political Science Review, 17, pp. 317-353. http://dx.doi.org/10.4324/9780429036606-2. $[28 / 01 / 21]$.

Kant, I. (1902ss.). Kant's gesammelte Schriften. Berlin et alia, Deutschland: hrsg. von der Königlich Preussischen, bzw. der Deutschen Akademie der Wissenschaften,

Kant, I. (1993), Acerca del refrán: "Lo que es cierto en teoría para nada sirve en la práctica" [Über den Gemeinspruch: Das mag in der Theorie richtig sein, taugt aber nicht für die Praxis, 1793], traducción de J. M. Palacios, M. F. Pérez López y R. R. Aramayo, Madrid, Tecnos.

Kant, I. (1994), Metafísica de las costumbres [Die Metaphysik der Sitten, 1797], traducción de A. Cortina Orts y J. Conill Sancho, Madrid, Tecnos.

Kant, I. (2007). Hacia la paz perpetua [Zum ewigen Frieden, 1795], traducción de R. R. Aramayo, Madrid, Ediciones Alamanda, CTK E-Books.

Kaufman, A. (1997), "Reason, Self-legislation and Legitimacy: Conceptions of Freedom in the Political Thought of Rousseau and Kant", The Review of Politics, 59, 1, pp. 25-52. http://dx.doi.org/10.1017/S0034670500027145. $[28 / 01 / 21]$.

Kelly, G. (2001), “A General Overview”, en: P. Riley (ed.), The Cambridge Companion to Rousseau, Cambridge: Cambridge University Press, pp. 8-56.

Kersting, W. (1992), “Kant's Concept of the State, en: H. Williams (ed.), Essays on Kant's Political Philosophy, United Kingdom, The University of Chicago Press, pp. 143- 165.

Kleingeld, P. (2009), “Kant's changing Cosmopolitanism”, en: A. O. Rorty \& J. Schmidt (eds.), Kant's Idea for a Universal History with a Cosmopolitan Aim. A Critical Guide, Cambridge, Cambridge University Press, pp. 171186.

Llano Alonso, Fernando H. (2012), "El humanismo cosmopolita como fundamento de la democracia universal", Derechos y libertades, 26, pp. 205-229. 
Lutz-Bachmann, M. (1997), "Kant's Idea of Peace and the Philosophical Conception of a World Republic", en: J. Bohman \& M. Lutz-Bachmann (eds.), Perpetual Peace. Essays On Kant's Cosmopolitan Ideal, Massachusetts, The MIT Press.

Riley, P. (2001), “Rousseau's General Will”, en P. Riley (ed.), The Cambridge Companion to Rousseau, Cambridge, Cambridge University Press, pp. 125-153.

Ripstein, A. (2009), Force and Freedom. Kant's Legal and Political Philosophy, Cambridge, Harvard University Press.

Rodríguez Aramayo, R. (2001), Immanuel Kant. La utopía moral como emancipación del azar. Buenos Aires, Argentina: Edaf.

Rodríguez Aramayo, R. (2018), “Introducción”, en Kant. I., Hacia la paz perpetua. Un diseño filosófico, Alamanda, CTK E-Books, Madrid, pp. $9-42$.

Rousseau, Jean-Jacques Rousseau (2017), El contrato social [Du Contrat Social ou Principes du droit politique, 1762], traducción española de G. Domecq, Buenos Aires, Colihue.

Rousseau, Jean-Jacques, "Resumen del Proyecto de paz perpetua del Abate Saint-Pierre" [Résumé du projet de paix perpétuelle de l'abbé SaintPierre] [RPP], en: Rousseau, Jean-Jacques, Escritos políticos, traducción de J. Rubio Carracedo, Madrid: Trotta, 2006, pp. 19-41.

Rousseau, Jean-Jacques, "Juicio sobre el proyecto de paz perpetua" [Jugement sur la paix perpétuelle, edición póstuma, en 1782] [JPP]. En: J-J. Rousseau, Escritos politicos, traducción de J. Rubio Carracedo, Madrid: Trotta, 2006, pp. 41-49.

Rubio Carracedo, J. Rousseau en Kant, Universidad Externado de Colombia, Bogotá, 1998, pp. 163-187.

Sánchez Madrid, N. (2016), “PPuede haber una fundamentación kantiana de los derechos humanos? Algunas consideraciones críticas”, Revista de Estudios Kantianos, 1, 2, pp. 191-206. http://dx.doi.org/10.7203/REK.1.2.8871. [28/01/21].

Santiago, T. (2004). Función y crítica de la guerra en la filosofía de I. Kant. México, México: Anthropos.

Tomassini, Fiorella. "La crítica de Kant a la doctrina de la guerra justa", Revista Portuguesa de Filosofía, vol. 75, 1, 2018, pp. 423-446. http://dx.doi. org/10.17990/RPF/2019_75_1_0423. [28/01/21].

Truyol y Serra, Antonio. "La guerra y la paz en Rousseau y Kant". Revista de Estudios Políticos, 8, 1979, pp. 47-62. 
Truyol y Serra, Antonio, "A modo de introducción: La paz perpetua de Kant en la Historia del Derecho de gentes", en Roberto Rodríguez Aramayo, Javier Muguerza y Concha Roldán (eds.), La paz y el ideal cosmopolita de la Ilustración. A propósito del bicentenario de Hacia la paz perpetua de Kant, Madrid, Tecnos, 1996, pp. 17-30.

Villegas Gutiérrez, Lina María. "Sobre la paz perpetua y el ideal cosmopolita: un diálogo entre Kant y Rousseau". Estudios Políticos, 47, 2015, pp. 30ss.

Williams, H. (1983). Kant's Political Philosophy. Oxford, England, Basic Blackwell.

Williams, H. (2011). "Metaphysical and not just Political”, en: S. Baiaus, S. Pihlström y H. Williams (eds.), Politics and Metaphysics in Kant, Cardiff, University of Wales Press, pp. 215-234. 